\title{
O NASCIMENTO DO PURGATÓRIO COMO PREPARAÇÃO DO BURGUÊS: ESPAÇOS CITADINOS, TEOLOGIA SOCIAL MEDIEVAL
}

\author{
Rogerio Ribeiro Tostes ${ }^{1}$
}

\section{Introdução: das origens do burgo ao surgimento das cidades medievais}

Ainda que a atividade do mercador nunca tenha deixado por completo de aparecer, no Ocidente, embrenhando-se por paragens as mais remotas e cambiando seus valiosos objetos deslocados de realidades que praticamente se desconheciam, foi apenas sob os auspícios do século XI que o papel desempenhado por ele assumiu a pulsação definitiva que redefiniria os espaços sociais, políticos e econômicos da Europa do medievo para a idade moderna. A partir das insipientes rotas comerciais, destacadas e tenuemente mantidas desde a Antigüidade, foi que se marcou o adensamento dos primitivos espaços urbanos a reflorescerem nas crescentemente ampliadas cidades medievais.

Assim, desde que se viabilizaram os trajetos comerciais, e a atividade itinerante do mercador passou a suprir demandas cada vez maiores para os nascentes centros urbanos europeus, num processo de interdependência naturalmente irreversível, o desenvolvimento social das cidades tornou-se diretamente vinculado ao ânimo das atividades de concentração e circulação financeira - embora ainda não possamos pensar num modus operandi capitalista, é neste momento que a monetarização das relações mercantis desenvolve sua grande

\footnotetext{
${ }^{1}$ Pós-graduando em Sociologia Política, UFPR. Bacharel em Direito, PUCPR, integrante do Grupo de Pesquisa de Direito de Integração e Conflito de Leis do Mercosul na mesma instituição. Graduando em História, UFPR. Bolsista de iniciação científica (CNPq), sob orientação da Prof. ${ }^{a}$ Dr. ${ }^{a}$ Fátima Regina Fernandes, professora adjunta de História Medieval no Departamento de História, UFPR. rogerio.tostes@gmail.com
} 
força de câmbio. Desta relevância vital para a existência citadina, são bem observáveis, nas próprias fontes selecionadas, em que progressão são destacados direitos e concessões no interesse por estimular a atuação dos mercadores em suas cidades e entrepostos comerciais:

Tendo visto os autos do nosso tribunal sobre o conflito ocorrido entre os mercadores de Lübeck por um lado e os recebedores da portagem de Bapaume por outro, parece que quando estes mercadores se dirigem à feiras da Champagne [...], não devem tomar obrigatoriamente a estrada de Bapaume, mas podem ir e vir com as suas mercadorias por onde quiserem, pagando as portagens habituais nos locais a que se destinam.

[...] Por esta razão ordenamos que vos oponhais firmemente a que os ditos mercadores sejam importunados em contrário ao conteúdo dos ditos autos. (ESPINOSA, F. Antologia de textos históricos medievais, p. 207.)

\begin{abstract}
A exemplo disso, também, vemos a preponderância dos italianos nos entrepostos orientais e as facilitações de suas atividades pelas autoridades locais:
\end{abstract}

Quando porém os Venezianos fazem comprar, recebendo alguma coisa por transação, de outro povo que não dos Venezianos, seja-lhes permitido recebê-las de acordo com as medidas reais a um preço dado. Não deverão os Venezianos pagar qualquer encargo por tudo isto, nem de acordo com o costume, nem por qualquer outra razão, ao entrar, estar, vender, comprar, permanecer, partir; em nenhum dos casos deverão pagar impostos [...] (Ibidem, p. 202.)

De outra maneira, algumas vezes a freqüência mercante veio a estabelecer, como no caso da "fundação" de Bruges, um fator de atração demográfica e estruturação institucional dos primitivos burgos fincados aos arrabaldes dos castelos e das villae senhoriais.

Rapidamente, portanto, o núcleo urbano evolui em complexidade e nas divisões de formas de trabalho - pois, é certo que as práticas de artesanato e a inovação dos meios de produção de consumo avançam industriosamente ${ }^{2}$, para ganhar relevo no 2 “A indústria é a causa primeira da transformação demográfica da qual o
nascimento e desenvolvimento das cidades flamengas são a conseqüência. O 
alargamento institucional programado por agentes cada vez mais capacitados para as transações, sejam elas administrativas, públicas ou estritamente comerciais, na vida das cidades medievais. Deste processo nascera a primeira instituição pública autônoma, vinculada à existência dos citadinos: a comuna. Daí que, o movimento comunal, como ficou conhecido pela historiografia moderna, ${ }^{3}$ tenha representado a primeira conquista marcante de uma classe que posteriormente se afirmaria como burguesia, gozando os direitos de exercer "livremente" suas atividades, e desde então, subordinados a seus próprios estatutos sobre a regulamentação urbana (muito embora o que se verifica para a maior parte das primeiras comunas, no centro e no norte do continente, à exceção das cidades italianas, é sempre um ambiente de grandes restrições por parte dos meios tradicionais de poder: clero e nobreza).

Em vários episódios, a aquisição das "cartas comunais" dependia do empenho das armas - em que se tornaram exemplares as insurgências em Le Mans, no século XI, e na Itália um século mais tarde, da Liga Lombarda contra Frederico Barba Ruiva -, ou simplesmente a partir de uma transação de compra e venda das liberalidades urbanas, financiada pelos próprios burgueses. Desse empenho conjunto, frutificam-se as primeiras corporações de ofício e as guildas, que tomam sobre si o encargo de organizar todos os processos da participação produtiva e elaboração hierárquica de seus agentes (logo, definição das novas divisões de trabalho). Naturalmente, esses grandes grupos em breve assumiram a preponderância na administração comunal e controlaram, com um poder paulatinamente sedimentado, os meios normais das técnicas jurídicas privadas e com elas influenciando a formação das esferas públicas de governo, das quais não eram ainda politicamente detentoras.

comércio ali nasceu da indústria, e não o contrário." VERLINDEN, C. Marchands ou tisserands? À propos des origines urbaines, Annales, 1972, pp.396-406 apud LE GOFF, Jacques, Cidade, in «Dicionário Temático do Ocidente Medieval», p. 222.

${ }^{3}$ LE GOFF, Jacques, op. cit., p. 224. 
Por último, a tipologia das cartas comunais não obedecia a um padrão uniforme, a ponto de ser repetido por todas as várias regiões continentais; ainda assim, em determinadas localidades, algumas dessas cartas se prestaram por modelos para a elaboração legal de outras, cujos interesses locais se conectavam e suportariam princípios regulamentais semelhantes.

\section{Espaços de encontro e aliança institucional: feiras, confrarias e guildas}

Mais tardiamente, com a estabilização dos espaços comunais e a solidez de suas estruturas políticas e sociais, a atividade comercial se alargou mais generosamente. Diante dos marcos citadinos as antigas rotas mercantes encontraram seus pontos estratégicos de distribuição e reabastecimento, estabelecendo, portanto, as primeiras grandes feiras de comércio e o afluxo periódico para as regiões que as sediavam. Desta forma, da Champagne à Flandres, significaram a coluna vertebral de todo o desenvolvimento e expansionismo burgueses a partir dos séculos XIII e XIV.

Paralelamente, e diretamente apoiadas na institucionalização comunal e na difusão das feiras de comércio medievais, a formação das confrarias e das guildas atuaram decisivamente para a conclusão do cenário governante das cidades. As confrarias, primeiro, se assentavam numa "razão social" vocacionada à prática religiosa e obras de caridade, mas a partir delas (cuja estrutura de produção dentro dos monastérios, rígida e altamente organizadas) produzia-se excedentes que eram levados aos núcleos urbanos e lá redistribuídos. Desse modelo extremamente eficiente se beneficiaram as corporações, alargando seus interesses a um nível de especialidade e de monopólio econômico que logo, como vimos, adquiririam também destaque político dentro das cidades.

Por suposto, a intensa elaboração e importância dessas corporações ou guildas alcançou postos destacados na nova ótica dos espaços de influência geopolítica, cada vez mais envolvidos, 
patrocinando monarcas e senhores feudais às vezes empobrecidos. Dessas associações, a mais destacada surge na duração da Liga Hanseática, que se pretende "uma confederação permanente de cidades, vilas e comunidades" (Dollinger apud PEDREROSANCHEZ, 169), cujo sucesso logo angariou o controle econômico de grandes rotas estratégicas e de quase a totalidade da navegação mercantil no Mar do Norte.

\section{Os câmbios da mentalidade: a reestruturação ideológica após o Ano Mil}

Ainda que, por volta dos séculos XII e XIII, o espaço citadino já estivesse bem organizado e preparado a receber a presença do homem burguês, persistia no plano ideológico barreiras que renegavam a sua absorção como parte ativa da existência espiritual das sociedades medievais. A Igreja, grande intermediária desses valores, manteve num primeiro momento seu apego ao esquema trifuncional, isolando o burguês como indivíduo marginal desse complexo social, porém, muito não resistiu, tendo afinal de recepcionar, mesmo que gradualmente, esse novo papel na ordem dos indivíduos coletivos. É deste lento processo que cuidaremos aqui.

Assim, atravessada a espessa camada da espiritualidade milenarista dos séculos X-XI, estigma da precariedade material de subsistência e da opressão ideológica da cristandade, o ocidente medieval assistiu a um grande conjunto de transformações no espaço das relações sociais. No escol dessas modificações, mormente situadas entre os séculos XII-XIII, o momento instituidor daquilo que atualmente a historiografia concorda em designar por feudalidade, fase de sedimentação formal dos vínculos antes ensaiados pela senhorialização das formas de poder e dominação, ${ }^{4}$ funcionalizando um novo elemento de unidade e demarcação do espaço político e social, útil em última instância a direção de crescimento que se

${ }^{4}$ BARTHÉlEMY, Dominique. Senhorio, in: LE GOFF, Jacques, SCHIMITT, Jean-Claude. Dicionário Temático do Ocidente Medieval, v. II, p. 466. 
experimentava naquele período. Um sentido de expansão e desenvolvimento dos antigos meios de vida, que por certo alimentava o movimento de renovação cultural de costumes, impondo logo uma dissonância das formas de gramática social em trânsito.

Entanto, para o alcance dessas alterações contou-se com o motor intelectual da Igreja, que, ao acompanhar de perto os câmbios estruturais da sociedade, sofreu internamente as repercussões desses mesmos gestos: a frouxidão do modus vivendi cristão à luz de novas exigências espirituais, requerendo desde então uma participação mais ativa dessas práticas. Também, a disputa alavancada pelas ordens espiritual e terrena tomaram um outro foco, com o vantajoso triunfo institucional da Igreja no controle mental das realidades sociais emergentes. Destarte, em acordo com essas novas realidades, a Igreja realinhou sua postura doutrinal no tocante a economia da salvação, alargando de certa forma seus quadros morais de aceitação para receber, ainda que em progressiva subalternidade, o pernicioso elemento do usurário, que até ali existia sob os interditos da salvação em decorrência de sua conduta perversa e espiritualmente nociva à harmonia cristã, seguramente apropriada ao corpo social teorizado pela perspectiva teológica.

\section{A construção teórica do espaço do purgatório}

Disso tudo, o surgimento do purgatório existe, pois, como fenômeno de readequação do ânimo salvífico cristão em face da irreprimível presença daquelas que praticavam a usura. Assim, o purgatório, primeiro como espaço intermediário entre o paraíso e o inferno, reflete claramente o pragmatismo do sistema trazido por esses novos valores. Ao se conceder uma segunda oportunidade na vereda da salvação, também se aproximava um grupo que, a despeito de suas práticas às vezes reprováveis, tomava um espaço cada vez maior na sociedade e nos efetivos materiais que permitiam a continuação da vida terrena. Por isso, ao se criar uma nova dimensão na geografia do imaginário espiritual, criava-se também uma 
alternativa inclusiva daqueles marginalizados ${ }^{5}$ até ali sem esperanças de redenção. No purgatório, local privilegiado para os que praticaram pecados de menor gravidade, estendia-se a chance de remissão daqueles para uma continuidade rumo a salvação eterna.

A sua travessia era marcada por terríveis obstáculos: atingiamna por meio de torturas e castigos semelhantes aos que se vislumbraria nos círculos infernais, com a alentadora diferença que naquele se permanecia sem a condição de perpetuidade do inferno, posto que, finalmente, a única saída possível era em direção ao paraíso. Aliás, pensando a geografia do Além, Jaques Le Goff escreve a propósito da descrição contida num tratado do monge de Saltey: "O purgatório é uma sucessão de lugares que se encontram no mesmo plano, percorre-se por meio de um caminho plano, sem subidas ou descidas. E trata-se de um lugar aberto, cujos limites se não vêem do qual se pode sair e fugir." ${ }^{6}$ Esta construção dirige-se a um momento em que a ideologia sobre o purgatório não se definira totalmente, durante o século XII. Para Le Goff, ele é importante em permitir entrever um conjunto de gestos e ações figurativas:

Na ideologia cristã medieval as linhas valorizadas são as do alto e do interior. O ideal, o programa proposto ao cristão, é o da subida e da interiorização. Aqui o espaço da narrativa é o do Além, de um novo Além que se coloca numa perspectiva de esperança e de reforço das possibilidades de salvação através da prova do purgatório, punitiva e purificadora. Os gestos são os da descida, do itinerário horizontal e da subida. Aliás, o movimento recomendado deve ser aqui inverso ao

\footnotetext{
${ }^{5}$ Ao elaborar uma "tipologia da marginalidade" no imaginário popular do ocidente medieval, Le Goff inclui os usurários entre o grupo dos "marginalizados propriamente ditos", ao passo que também os entenda próximos "da categoria dos excluídos".

LE GOFF, J. O Maravilhoso e o Quotidiano no Ocidente Medieval. Lisboa: Ed. Setenta, 1990, p. 170.

${ }^{6}$ Ibidem, p. 64.
} 
movimento realizado, pois que se trata de escapar a esse interior mau. $\mathrm{O}$ processo bom é portanto entrar-atravessar-sair. ${ }^{7}$

No entanto, a construção ideológica de um espaço intermediário na "sociedade dos mortos" não foi uma criação repentina, como mera resposta às contingências da salvação. Trata-se, antes, de uma lenta elaboração que se inicia, na tradição latina, com Santo Agostinho e São Gregório Magno, cujo processo se torna mais acelerado somente a partir do século XII, numa passagem de tendências ideológicas alto-medievais, onde a Igreja, ao acompanhar as transformações comuns, adaptava-se à existência de uma nova categoria de indivíduos sociais - o burguês.

La cupidigia è il più abominevole dei vizi. "Tu puoi ricevere la croce dal papa, attraversare el mare, combattere contro i pagani, conquistare el Sacro Sepolcro e morire per la causa di Dio e persino essere sepolto nel Sacro Sepolcro - così si rivolge a un usuraio atterito dalla sua predica el francescano tedesco Bertoldo di Ratisbona - eppure, nonostante tutta la tua santità, la tua anima è perduta." ${ }^{8}$

Assim, se no princípio sua cupidez era a razão de sua ruína espiritual, mais tardiamente seu papel foi reavaliado. Era ele quem, sem um posto preciso no esquema da trifuncionalidade, existia sob a contrição espiritual da usura, ou seja, a cobrança de juros excessivos pelo empréstimo de dinheiro (portanto, condenação taxativa mas não generalizada), compondo um incômodo paradoxo no ordenamento dos atores sociais elaborado pela Igreja, ao manter sua atividade econômica ligada ao ganho do lucro, atividade tal que ao ser condenada era também reconhecida como substancial para a gravitação econômica da sociedade.

Esta condição levou a se pensar uma flexibilização de seus termos, adotando limites em que se poderiam averiguar a monta excessiva dos juros, portanto, passível de prática usurária. Mas a

${ }_{8}^{7}$ LE GOFF, op. cit., p. 68.

8 GUREVIC, Il mercante, in: LE GOFF. [org.] L'uomo medievale. Roma: Ed. Laterzi, 1993, p. 282. 
ilustração desses limites também era incerta, variando em acordo com determinada região, e muitas vezes atuando enquanto indicador de seus caracteres econômicos estruturais, "[...] eram um barômetro parcial da actividade economia". ${ }^{9}$ Por isso, sob os termos da "taxa de mercado", a usura se tornava mais aceitável, e até mesmo reconhecida, como parte legítima ao seu credor. A restrição continua, repetimos, para aqueles que tomam prática manifesta da usura, como declarara o III Concílio de Latrão em 1179, ou que adotava nesta prática o hábito profissional.

\section{Das dissonâncias ideológicas à utilidade social do purgatório}

Desta maneira, não seria incorreto apreender que o aceleramento da construção teórica do purgatório atuou em simultaneidade à necessidade de se inserir, como referimos, a recente categoria dos burgueses. Contudo, mesmo sua legitimação, sofreu reveses nos debates internos da Igreja, havia de uma parte aqueles que amparavam um discurso de aceitação daquelas novas práticas em oposição àqueles que a censuravam veementemente, como condescendência nociva e demasiadamente permissiva para os padrões da religiosidade cristã. Logo após o século décimo, com o ano mil da cristandade, dá-se o surgimento dos primeiros teóricos "vanguardistas", professando acreditarem no papel da burguesia, cabendo-lhe portanto alguma forma de ingresso no projeto de salvação. Como extensão natural, defendia-se a viabilidade dogmática do purgatório como espaço de trânsito na geografia além-terrena. Seus principais defensores se alinhavam entre os membros das ordens mendicantes, como os dominicanos, vez que para os cistercienses, cujo poder político dentro da Igreja tinha volume, a ponto de influenciar com peso a complementação teológica do purgatório, rejeitava sempre que possível, embora não por muito tempo, a inclusão do burguês nas perspectivas da redenção final da alma.

${ }^{9}$ LE GOFF. A Bolsa e a Vida: Economia e Religião na Idade Média. Lisboa: Teorema, s/d, p. 89. 
Mas, muito embora o purgatório representasse um fator de esperança ao processo de salvação, ainda era necessário que o burguês contrito atingisse a remissão de seus pecados, confessandoos, arrependendo-se deles, e mesmo restituindo aquilo que devido a outrem, como condição de aceitação. Neste sentido, o largo esforço doutrinal daqueles que invectivavam os valores cristãos da moderação e da caridade, no aperfeiçoamento do caráter e da integridade espiritual. A partir, pois, de nomes importantes, como os pregadores Etiénne de Bourbon e Cesareo de Heisterbach, registrando suas prédicas através de um estilo de retórica bastante apropriado, nas chamadas exempla: figuração de curtas histórias de forte conteúdo moral, narrativa pedagógica, orientando a participação social do burguês no sentido de corrigi-lo para a aceitação do plano divino/salvacionista, onde se indicava a perdição daquele usurário, imerso em perfídia e soberba, que era cruelmente ceifado da vida sem meios de expiar seus pecados pregressos, condenado por isso à perdição eterna.

Finalmente, é em São Tomás, enquanto importante teólogo da cristandade medieval, que detectamos o grande defensor de uma ideologia acerca do purgatório. A propósito de seguir a tradição erudita aristotélica e boeciana, ele re-elabora a semântica do conceito de trabalho na sociedade medieval, onde a atividade desempenhada pelo burguês não apenas encontra integração como também descobre um papel necessário e substancial para a existência da ordem social; daí uma maior complexização das divisões de trabalho na inserção da figura do burguês como indivíduo socialmente desejável, que resultou, no limite, na própria capacidade posterior da acumulação de capital a partir desses elementos. Desta sorte, a Igreja mesma abre meios de reabilitação desse burguês empedernido pela atividade usurária, aceitando (e estimulando que se fizessem) doações vultosas ao patrimônio clerical, as compras de bula, etc., como meio de atingir a remissão e a reintegração na comunidade da salvação.

Assim, se por um lado os cistercienses eram recalcitrantes em admitir a inclusão da burguesia no plano dos remidos, por outro, os 
dominicanos retalharam antigas doutrinas no intuito de absorver aquela categoria, legitimando seu acesso, mesmo que pela "entrada dos fundos", ao universo da salvação. Naturalmente, o discurso mais flexível do esquema dominicano acabou por se impor contra a tradição anciã defendida pelos cistercienses, rompendo contra a predominância conceitual que se prolongava desde os séculos XI-XII, que insistia em ignorar a pungente variedade da realidade concreta. ${ }^{10}$

Por fim, acabaria por não ser inapropriado inferir que, se a elaboração conceitual do purgatório, bem como uma sua acelerada progressão teórica a partir do século XII, andaram pari passu de um efeito prático de se assimilar uma nova categoria social, que deslocada dos esquemas tradicionais da trifuncionalidade, exigiram novo acompanhamento e novo estatuto doutrinário para a apreensão transigente daquela realidade histórica, que embora sendo essencialmente medieval, começara a marcar as vias fundamentais da sociedade moderna.

\section{Nota de conclusão}

Sabemos, pois, que a construção de um ambiente urbano oportuno ao desenvolvimento do burguês, e a aparatagem institucional que the deu seguido suporte, conformam uma pletora de razões indispensáveis na compreensão da dinâmica burguesia/cidade.

$\mathrm{O}$ afortunado encontro das grandes delimitantes políticas e econômicas européias, das passagens dos séculos XI ao XIV, embora constituintes de um panorama irregular e multivalente, foi capaz de preparar a assunção das novas realidades que se precipitariam nos quinhentos e no expansionismo marítimo das grandes conquistas. Foi sob seu cruzamento que se gestaram as novas práticas comerciais que finalmente engendrariam o capitalismo moderno, e com conseqüências tão profundas para a dimensão das sociedades pósfeudais, que o cambiamento dos antigos valores e práticas jurídicas (sumariamente, as de caráter comercial e creditório) conduziriam por

${ }^{10}$ GUREVIC, op. cit., p. 275. 
si mesmas a uma nova percepção do fenômeno social, cuja centralidade nos moldes privatistas condenaria, séculos mais tarde, os princípios e a tônica das relações feudo-vassálicas à sua inteira extinção.

\section{BIBLIOGRAFIA}

BARTHÉLEMY, Dominique. «Senhorio» in: LE GOFF, Jacques, SCHIMITT, Jean-Claude. Dicionário Temático do Ocidente Medieval. 2 volumes. Coord. Hilário Franco Júnior. Bauru, SP: EDUSC, 2006.

DUBY, Georg. Europa en la Edad Media. Barcelona: Paidos, s.d. GROSSI, Paolo. L'ordine giuridico medioevale. Roma/Bari: Laterza, 1995.

GUREVIC, Aron Ja. «Il mercante» in: LE GOFF. [org.] L'uomo medievale. Tradotto per Clara Castelli. Roma: Ed. Laterzi, 1993.

LE GOFF, Jacques. A Bolsa e a Vida: Economia e Religião na Idade Média. Lisboa: Teorema, s/d.

- El Nacimiento del Purgatorio. Versión de Francisco Pérez Gutiérrez. Madrid: Taurus, s/d.

. O Maravilhoso e o Quotidiano no Ocidente Medieval. Tradução de António José Pinto Ribeiro. Lisboa: Ed. Setenta, 1990.

LE GOFF, Jacques, SCHIMITT, Jean-Claude. Dicionário Temático do Ocidente Medieval. 2 volumes. Coord. Hilário Franco Júnior. Bauru, SP: EDUSC, 2006. 